\title{
Regioselective transformation of alkynes catalyzed by a copper hydride or boryl copper species
}

$\operatorname{AUTHOR}(\mathrm{S})$ :

Fujihara, Tetsuaki; Semba, Kazuhiko; Terao, Jun; Tsuji, Yasushi

\section{CITATION:}

Fujihara, Tetsuaki ... [et al]. Regioselective transformation of alkynes catalyzed by a copper hydride or boryl copper species. Catalysis Science \& Technology 2014, 4(6): 1699-1709

\section{ISSUE DATE:}

2014-03-05

URL:

http://hdl.handle.net/2433/199872

\section{RIGHT:}

This journal is (C) The Royal Society of Chemistry 2014.; This is not the published version. Please cite only the published version.; この論文は 出版社版でありません。引用の際には出版社版をご確認ご利用くださ い。 


\title{
Perspective
}

\section{Regioselective transformation of alkynes catalyzed by a copper hydride or boryl copper species}

\author{
Tetsuaki Fujihara, Kazuhiko Semba, Jun Terao and Yasushi Tsuji*
}

\begin{abstract}
This review summarizes the transformation of alkynes using a copper hydride $(\mathrm{Cu}-\mathrm{H})$ or boryl copper $(\mathrm{Cu}-$ B) species as the active species. The semihydrogenation, hydrocarboxylation, and hydroboration of alkynes have been developed using $\mathrm{Cu}-\mathrm{H}$ as the active species. The hydroboration, diboration, carboboration and boracarboxylation of alkynes involve the $\mathrm{Cu}$-B species. These transformations afforded multi-substituted alkenes that are potentially good intermediates in organic synthesis. The key to the regioselective transformation is the addition of the $\mathrm{Cu}-\mathrm{H}$ or $\mathrm{Cu}-\mathrm{B}$ species to an alkyne, to afford the corresponding alkenylcopper intermediate regioselectively.
\end{abstract}

\section{Introduction}

Copper complexes are highly valuable reagents in organic synthesis. ${ }^{1}$ Organocuprates are one of the most versatile synthetic tools in the total synthesis of natural products because their reactions proceed with chemo-, regio-, and stereoselectivity. To date, copper complexes can catalyze diverse organic transformations such as carbon-carbon and carbon-heteroatom bond formation. ${ }^{1}$ Similar to the stoichiometric organoquprate system, copper-catalyzed reactions proceeded regio- and stereoselectively. In addition, activity and selectivity of the catalytic reaction can be controlled by ligand employed.

Herein, we reviewed the transformation of alkynes using a copper hydride $(\mathrm{Cu}-\mathrm{H})^{2}$ or boryl copper $(\mathrm{Cu}-\mathrm{B})^{3}$ species as the catalytically active species. The key to the successful transformation is the regioselective addition of $\mathrm{Cu}-\mathrm{H}$ or $\mathrm{Cu}-\mathrm{B}$ species to an alkyne, giving the corresponding alkenylcopper intermediate (Scheme 1). The regioselectivity can be controlled by directing effects of alkynes and the steric and electronic effect of ligands on the copper. The reactions of the alkenylcopper with various electrophiles such as alcohol, carbon dioxide $\left(\mathrm{CO}_{2}\right)$, or alkyl halide afforded the corresponding multi-substituted alkenes that are potentially good intermediate in organic synthesis. The scope and reaction mechanism of these reactions are discussed.

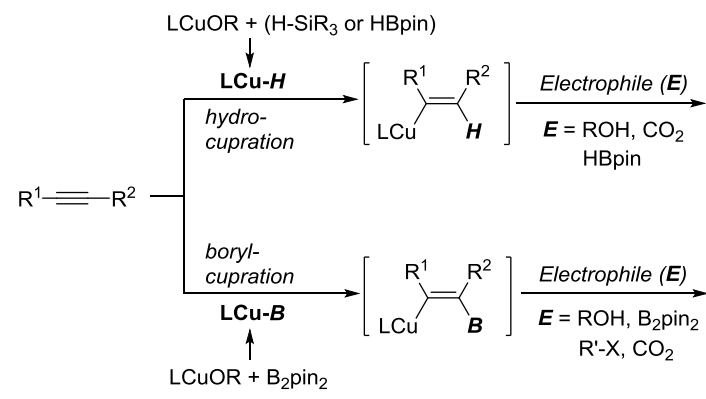

Scheme 1 Generation of alkenylcopper intermediate by the reaction of an alkyne with a copper hydride or a boryl copper species.

\section{Reductive transformation of alkynes catalyzed by a copper hydride species}

\subsection{Synthesis of copper hydride complexes}

The first example of a fully characterized copper hydride complex was reported by Churchill and Osborn in $1971 .^{4}$ The reaction of a tetrameric copper alkoxide in the presence of triphenylphosphine $\left(\mathrm{PPh}_{3}\right)$ afforded a hexameric copper hydride complex $\left[\mathrm{CuH}\left(\mathrm{PPh}_{3}\right)\right]_{6}$ (Scheme 2a). The structure of the complex was established by X-ray diffraction analysis; the six copper atoms were located at each position of an octahedron with an average $\mathrm{Cu}-\mathrm{Cu}$ bond distance of $2.599 \AA$. Stryker and coworkers found that the complex effectively worked for the 1,4reduction of $\alpha, \beta$-unsaturated carbonyl compounds. ${ }^{5}$ They also reported a conveniet procedure for the multi-gram scale preparation of $\left[\mathrm{CuH}\left(\mathrm{PPh}_{3}\right)\right]_{6}$, and the complex is now commercially available as Stryker's reagent (Scheme 2b). ${ }^{6}$ In 2004, Sadighi and co-workers reported a copper complex with an $\mathrm{N}$-heterocyclic carbene $(\mathrm{NHC})^{7}$ as the ligand; the reaction of $\operatorname{IPrCu}(\mathrm{O} t-\mathrm{Bu})$ with a hydrosilane afforded the corresponding copper hydride complex. ${ }^{8}$ The X-ray crystallographic analysis showed that the complex has a dimeric structure bridged by two hydrogen atoms. The ${ }^{1} \mathrm{H}$ NMR signal assigned to the $\mathrm{Cu}-\mathrm{H}$ appeared at $\delta 2.36 \mathrm{ppm}$ in benzene- $d_{6}\left(\mathrm{C}_{6} \mathrm{D}_{6}\right)$. Nolan and coworkers reported (NHC)CuH complexes showed a good catalytic activity in the hydrosilylation of various carbonyl compounds. ${ }^{9}$ We found that a copper hydride complex with a bowl-shaped phosphine as the ligand showed the preferential reduction of a bulky ketone in the presence of an aldehyde. ${ }^{10}$ 


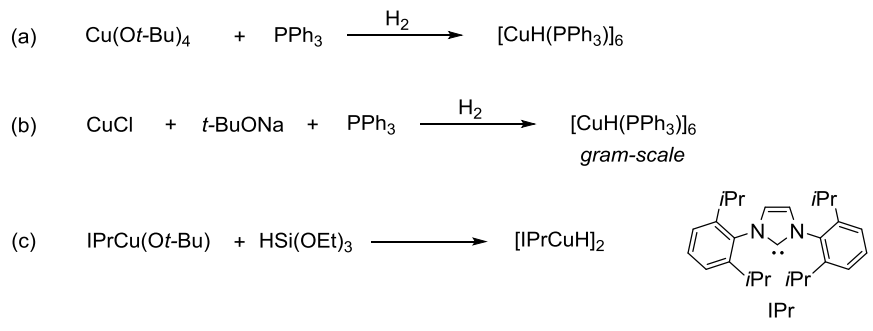

Scheme 2 Synthesis of copper-hydride complexes

\subsection{Copper-catalyzed semihydrogenation of alkynes using hydrosilane}

The semihydrogenation of internal alkynes is a crucial methodology to afford $(Z)$-alkenes that are often found in many biologically active compounds. The Lindlar catalyst ${ }^{11}$ is well known and most efficient; however, it often suffers from Z/E isomerization, low chemoselectivity, and poor reproducibility. On the other hand, several homogeneous catalysts showed good $Z$-selectivity in the semihydrogenation of alkynes. ${ }^{12}$ Recently, homogeneous palladium catalysts have been extensively developed. ${ }^{13}$

Regarding copper complexes, a pionirring work on the stoichiometric reduction of alkynes usng $\left[\mathrm{CuH}\left(\mathrm{PPh}_{3}\right)_{6}\right]$ and water was reported by Stryker (Stryker's reagent, eq 1). In the reactions, $(Z)$-alkenes were selectively obtained in good yields. ${ }^{14}$

$$
\mathrm{R}^{1}=\mathrm{R}^{2} \quad \frac{\mathrm{H}_{2} \mathrm{O}(5 \text { equiv) }}{\text { benzene, } \mathrm{RT}-80^{\circ} \mathrm{C}} \underset{\left.\left.\mathrm{PPh}_{3}\right)_{6}\right](0.5 \text { equiv) }}{\mathrm{R}_{2}^{1}} \mathrm{R}^{2}
$$

We found that the semihydrogenation of alkyne (1) proceeded in the presence of a mixture of polymethylhydrosiloxane (PMHS) and $t$ - $\mathrm{BuOH}$, as the reducing reagent at room temperature (Scheme 3). ${ }^{15}$ Employing $\mathrm{Cu}(\mathrm{OAc})_{2} \cdot \mathrm{H}_{2} \mathrm{O}$ and a xantphos ligand bearing 3,5-di-(trifluoromethyl)phenyl moieties $\left(\mathrm{CF}_{3} \mathrm{Ar}-\mathrm{Xan}\right)$, the reaction of 1-phenyl-1-propyne and 1-phenyl1-hexyne afforded to the corresponding ( $Z$ )-alkenes (2) in high yields. Diverse functionalities such as hydroxyl, chloro, cyano and phthalimido groups were tolerated in the reaction. Diphenylacetylene was also reduced to cis-stilbene in 93\% isolated yield without the formation of bibenzyl. To our delight, the bromo and iodo moieties on the aromatic ring were intact; they may undergo the oxidative addition reaction with lowvalent transition metal catalyst centers such as $\operatorname{Pd}(0) .{ }^{13}$ The reaction of 6-dodecyne smoothly afforded to the corresponding $(Z)$-alkene in a good yield and with good regioselectivity.

The selective semihydrogenation of terminal alkynes is known to be difficult owing to their overreduction to the corresponding alkanes. Although $\mathrm{Cu}(\mathrm{OAc})_{2} \cdot \mathrm{H}_{2} \mathrm{O} / \mathrm{CF}_{3} \mathrm{Ar}-\mathrm{Xan}$ catalyst system was not active enough to achieve the complete conversion of terminal alkynes, the catalyst system with NHC ligand $\left({ }^{\mathrm{Cl}} \mathrm{IPr}\right.$ or ${ }^{\mathrm{Me}} \mathrm{IPr}$ ) was effective (Scheme 4). The reaction of phenylacetylene afforded styrene in $92 \%$ yield without the formation of ethylbenzene. Other aromatic and aliphatic terminal alkynes were also selectively semihydrogenated. Lalic and co-workers also reported the copper-catalyzed semihydrogenation of alkynes using $\mathrm{Cu}-\mathrm{NHC}$ complexes and hydrosilane as the reducing agent. ${ }^{16}$

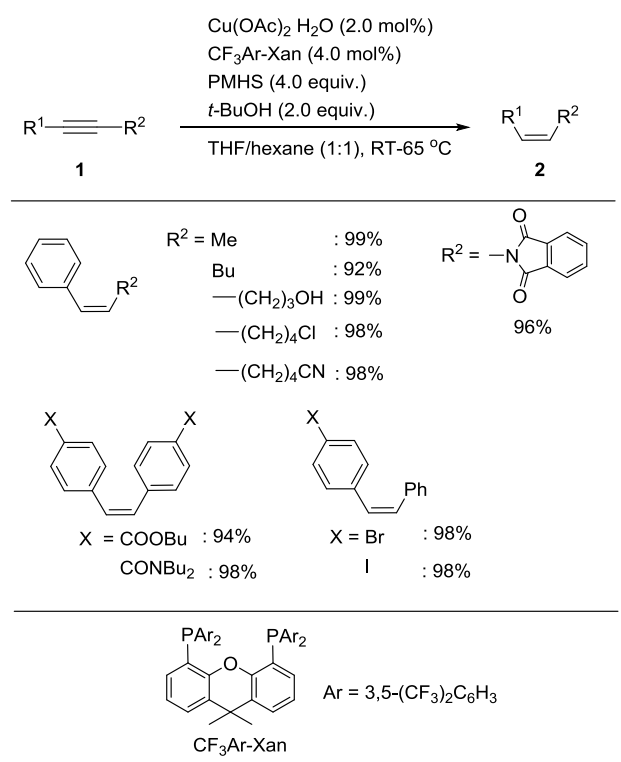

Scheme 3 Copper-catalyzed semihydrogenation of internal alkynes

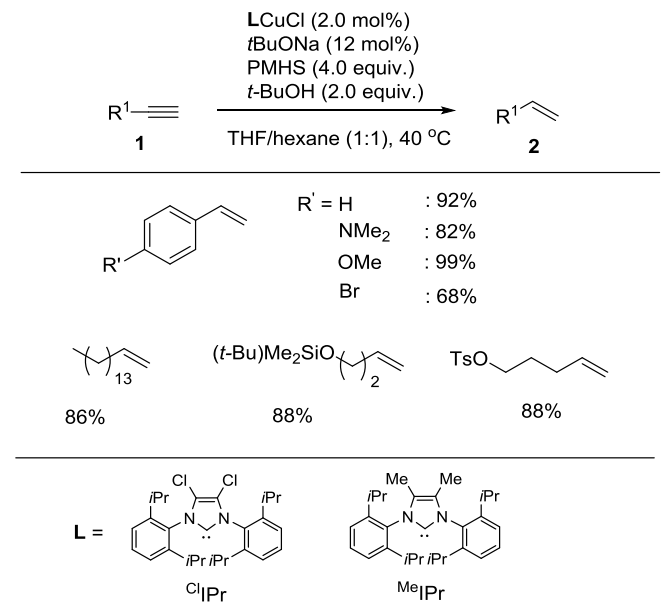

Scheme 4 Copper-catalyzed semihydrogenation of terminal alkynes

A possible catalytic cycle for the copper-catalyzed semihydrogenation of alkynes is shown in Scheme 5. A copper(I) hydride species (A) is generated by the reaction of the catalyst precursor with the silane. The addition of $\mathbf{A}$ to alkynes (1) may be much faster than that to alkenes and affords an alkenylcopper intermediate (B) stereoselectively via syn-addition (step a). Next, the protonation of $\mathbf{B}$ with $t$-BuOH affords (Z)-alkenes (2) selectively with the concomitant formation of $\mathrm{LCu}(\mathrm{O} t-\mathrm{Bu})(\mathbf{C})$ (step b). Finally, the $\sigma-$ bond metathesis of $\mathbf{C}$ with the silane regenerates $\mathbf{A}$, and the catalytic cycle is completed (step c).

\subsection{Copper-catalyzed hydrocarboxylation of alkynes using carbon dioxide and a hydrosilane}

$\mathrm{CO}_{2}$ is a readily available and renewable chemical feedstock; however, the thermodynamic stability limits its widespread use in chemical reactions. Transition-metal catalysts are required for effective utilization of $\mathrm{CO}_{2}{ }^{17}$ To realize useful transformations of $\mathrm{CO}_{2}$, the hydrocarboxylation of carbon-carbon multiple bonds using $\mathrm{CO}_{2}$ is also very promising. ${ }^{18,19}$ In 2008 , the first catalytic hydrocarboxylation using $\mathrm{CO}_{2}$ was independently reported by 


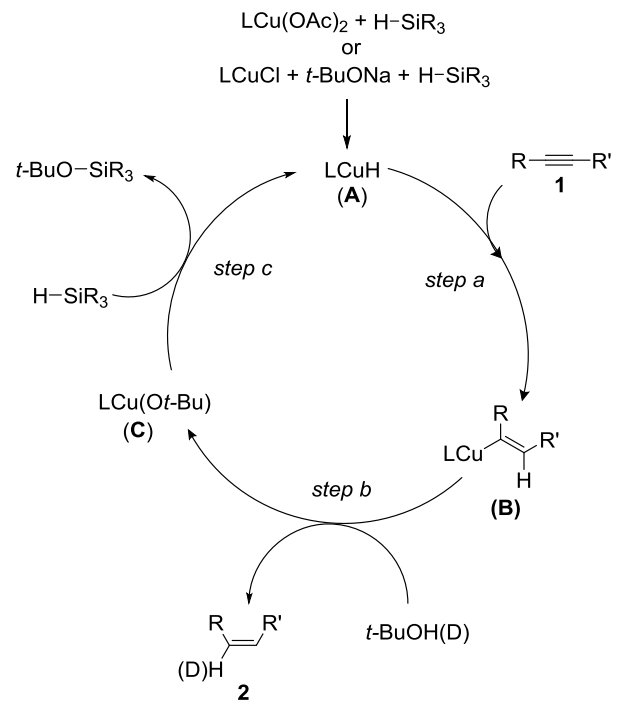

Scheme 5 A possible catalytic cycle for the copper-catalyzed semihydrogenation of alkynes.

Iwasawa and Rovis. Iwasawa and co-workers found that a palladium complex with a silyl pincer ligand catalyzed the hydrocarboxylation of allene using triethylaluminum as the reducing agent. ${ }^{18 a}$ Rovis and co-workers reported the nickelcatalyzed hydrocarboxylation of styrene derivatives using diethylzinc as the reducing agent. ${ }^{18 \mathrm{~b}}$

We reported the first catalytic hydrocarboxylation of alkynes (1) with $\mathrm{CO}_{2}$ in the presence of a copper catalyst (Scheme 6). ${ }^{19 \mathrm{a}}$ The reactions of alkynes were carried out using $\mathrm{HSi}(\mathrm{OEt})_{3}$ as the reducing agent and $\mathrm{LCuF}\left(\mathrm{L}=\mathrm{IMes}\right.$ or $\left.{ }^{\mathrm{Cl}} \mathrm{IPr}\right)$ as the catalyst in dioxane or hexane as the solvent. The corresponding $\alpha, \beta$ unsaturated carboxylic acids (3) were obtained in good yields with good $E$-stereochemistry. In the case of diphenylacetylene, the product was obtained in $72 \%$ yield. The alkynes bearing both electron-rich and electron-poor aryl moieties afforded the corresponding products in good yields. Importantly, chloro, bromo, and alkoxycarbonyl functionalities were tolerated in the reaction. The reaction of 1-phenyl-1-propyne afforded a mixture of hydrocarboxylated products with moderate regioselectivity in the presence of ${ }^{\mathrm{Cl}} \mathrm{IPrCuF}(2.5 \mathrm{~mol} \%)$ in hexane. The reactions of unsymmetrical alkynes with cyclohexyl and $t$-butyl groups gave the corresponding single regioisomers in good to high yields. Later, Ma and co-workers reported the nickel-catalyzed hydrocarboxylation of alkynes using diethylzinc as the reducing agent. ${ }^{19 \mathrm{~b}}$ The reaction was very useful; however, the uses of strong and extremely air-sensitive reducing agents were indispensable in the reactions.

To gain insights into the reaction mechanism, fundamental catalytic steps in the hydrocarboxylation utilizing silanes were examined by performing the stoichiometric reactions (Scheme 7). When ${ }^{\mathrm{Cl}} \mathrm{IPrCuF}$, the catalyst precursor in Scheme 6, was treated with an excess amount (4 equiv) of the silanes such as PMHS or $\mathrm{HSi}(\mathrm{OEt})_{3}$ in $\mathrm{C}_{6} \mathrm{D}_{6}$, an immediate color change from colorless to bright orange was observed. The ${ }^{1} \mathrm{H}$ NMR spectrum showed clean formation of ${ }^{\mathrm{Cl}} \mathrm{IPrCuH}$ (A) with a diagnostic proton resonance of $\mathrm{Cu}-\mathrm{H}$ at $\delta 2.39 \mathrm{ppm}$, which is close to the reported value of $\mathrm{IPrCuH}$ at $\delta 2.36 \mathrm{ppm}^{8}$ The reaction of an aromatic alkyne with $\mathbf{A}$ for $2.5 \mathrm{~h}$ at room temperature smoothly afforded the corresponding alkenylcopper complex $(\mathbf{B})$. The reaction of $\mathbf{B}$ with $\mathrm{CO}_{2}$ (balloon) was very slow at room temperature; however, the reaction proceeded smoothly at a higher reaction temperature $\left(65^{\circ} \mathrm{C}\right)$ for $12 \mathrm{~h}$. Finally, the reaction of $\mathbf{C}$ with an excess amount ( 4 equiv) of $\mathrm{HSi}(\mathrm{OEt})_{3}$ at room temperature cleanly afforded the copper hydride complex (A). Based on the results of the stoichiometric reactions, a plausible reaction mechanism is proposed as follows: A copper(I) hydride species is generated in situ from $\mathrm{LCuF}\left(\mathrm{L}=\mathrm{IMes}\right.$ or $\left.{ }^{\mathrm{Cl}} \mathrm{IPr}\right)$ and a hydrosilane via the strong silicon-fluorine interaction. The syn addition of the copper hydride to an alkyne initiates the catalytic cycle and affords the alkenylcopoper intermediate stereoselectively. Then, the insertion of $\mathrm{CO}_{2}$ affords the corresponding copper carboxylate intermediate. Finally, the $\sigma$-bond metathesis of $\mathbf{C}$ with the hydrosilane gives the corresponding silyl ester, and the $\mathrm{Cu}-\mathrm{H}$ species is regenerated. The insertion of $\mathrm{CO}_{2}$ required a higher reaction temperature $\left(65{ }^{\circ} \mathrm{C}\right)$, whereas the other stoichiometric reactions proceeded at room temperature. Thus, the insertion of $\mathrm{CO}_{2}$ must be the rate-determining step.

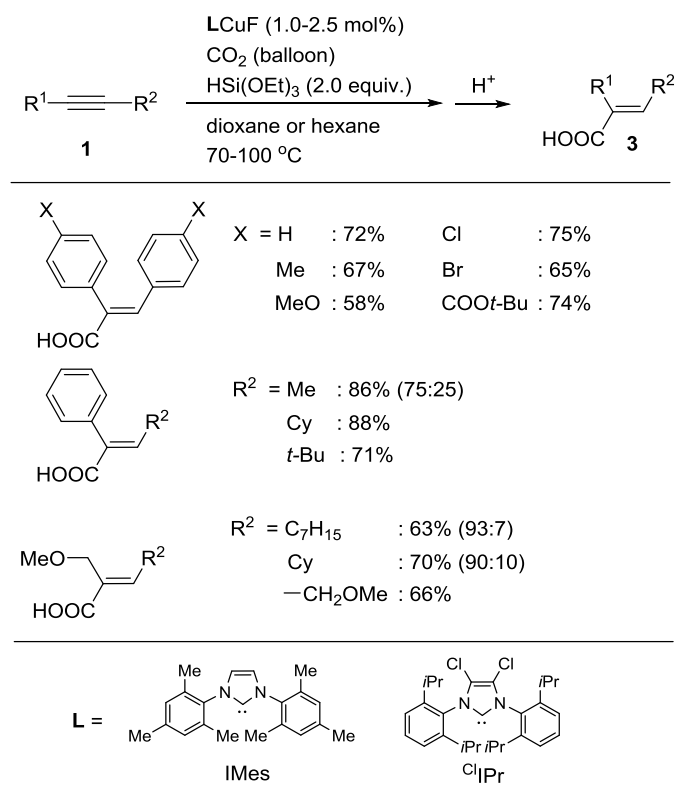

Scheme 6 Copper-catalyzed hydrocarboxylation of alkynes

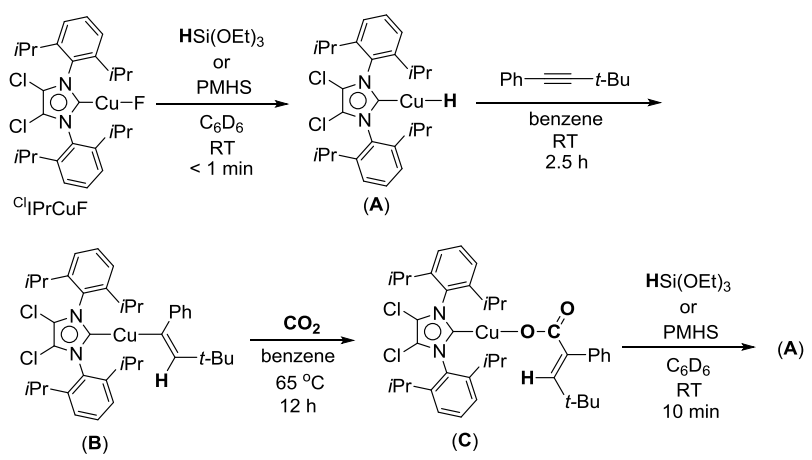

Scheme 7 Stoichiometric reactions for the relevant to mechanism.

\subsection{Copper-catalyzed hydroboration of unsymmetrical internal alkynes using pinacolborane (HBpin)}

Hydroboration is a robust and practical synthetic method for the synthesis of organoboranes. ${ }^{20}$ In particular, the hydroboration of 
alkynes is interesting because the products (alkenyl boranes) are potent starting materials for the Suzuki-Miyaura cross-coupling reaction. ${ }^{21}$ It is well known that the hydroboration of terminal alkynes proceeds regio- and stereoselectively. ${ }^{22}$ In the case of unsymmetrical internal alkynes as the substrates, position for introducing a boron moiety has to be controlled (eq 2). However, these reactions often suffer from low regioselectivity even in the presence of a catalyst. ${ }^{23}$

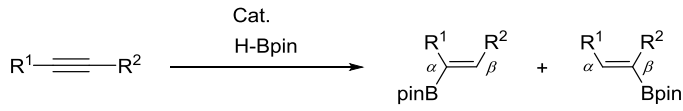

Lipshutz and co-workers reported that a copper complex catalyzed the hydroboration of alkynoates (Scheme 8). ${ }^{24}$ The reaction of 1,2bis(diphenylphosphino)benzene (BDP) ligand (1 mol\%) with in situ generated $\mathrm{CuH}$ afforded [(BDP)CuH] (Method A, Scheme 8). In addition, the reaction was also carried out with commercially available Stryker's reagent (2 mol\%) (Method B, Scheme 9). Both the reactions smoothly afforded the desired products with excellent $Z / E$ ratios.

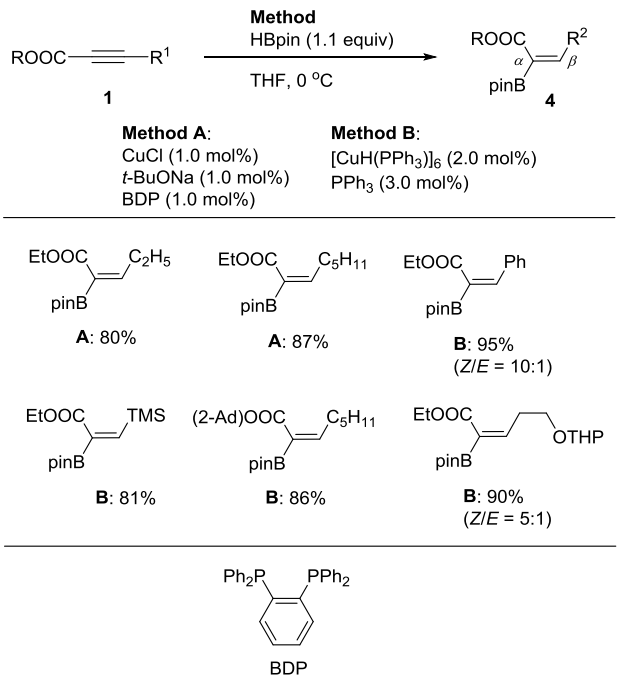

Scheme 8 Copper-catalyzed regioselective hydroboration of alkynoates.

We found that the hydroboration of unsymmetrical internal alkynes (1) proceeded when pinacolborane (HBpin) was used in the presence of a copper catalyst system $(\mathrm{CuCl} / t-\mathrm{BuONa})$ and xantphos derivatives bearing 3,5-xylyl moieties (MeAr-Xan) (Scheme 9). ${ }^{25}$ The reaction of 1-phenyl-1-hexyne afforded the corresponding alkenyl borane (4) in $92 \%$ overall yield and with high regioselectivity. The reaction of various internal alkynes afforded the corresponding products regioselectively. Both the electron-donating and withdrawing groups on the aryl ring were tolerated while maintaining high yields and regioselectivity. The alkynes with ester and amide functionalities instead of aromatic substituents afforded the corresponding $\alpha$ products in high yields and with high regioselectivity. Furthermore, the alkynes bearing $\mathrm{O}$ and $\mathrm{N}$ atoms at the propargylic position provided the corresponding $\alpha$-products in good yields and with high regioselectivity when $\mathrm{CF}_{3} \mathrm{Ar}-\mathrm{Xan}$ instead of MeAr-Xan was used as the ligand.

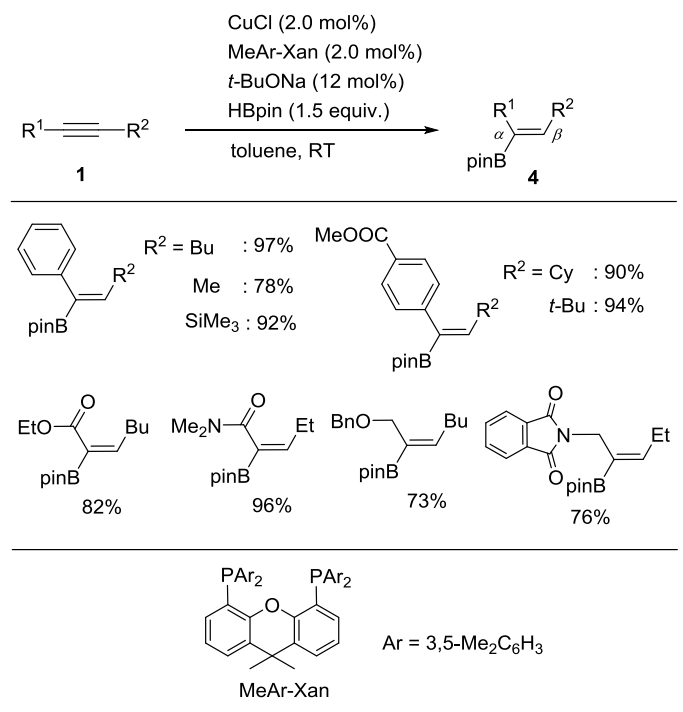

Scheme 9 Copper-catalyzed hydroboration of unsymmetrical internal alkynes employing $\mathrm{CuCl} / \mathrm{MeAr}-\mathrm{Xan}$.

A possible catalytic cycle for the $\mathrm{Cu}$-catalyzed hydroboration using HBpin is shown in Scheme 10. First, $\mathrm{LCu}(\mathrm{O} t-\mathrm{Bu})$ is generated from $\mathrm{LCuCl}$ and $t$-BuONa. As indicated by the clean stoichiometric reaction of ${ }^{\mathrm{Cl}} \mathrm{IPrCu}(\mathrm{O} t-\mathrm{Bu})$ with $\mathrm{HBpin}$, a copper hydride may be the active species in the hydroboration when HBpin is used. The syn addition of the copper hydride to the alkynes affords the alkenylcopper species with high regioselectivity because of the directing effect of the substituent. Finally, the reaction of the alkenylcopper intermediate with HBpin affords the corresponding $\alpha$ borylated product (4) and completes the catalytic cycle by regenerating the active catalytic species, $\mathrm{LCu}-\mathrm{H}(\mathbf{A})$ (step b). In addition, the Xan ligands are effective for the $\alpha$-borylation reactions because their bulkiness hinders the aggregation of the $\mathrm{Cu}-\mathrm{H}$ species. ${ }^{2}$ In relevance to step $\mathrm{b}$, the reaction an alkenylcopper complex bearing ${ }^{\mathrm{C}} \mathrm{IPr}$ ligand with $\mathrm{HBpin}$ at $0{ }^{\circ} \mathrm{C}$ instantaneously afforded the corresponding hydroboration product in quantitative yield, and the corresponding copper hydride complex was provided cleanly, as confirmed by the ${ }^{1} \mathrm{H}$ NMR measurement (eq. 3).
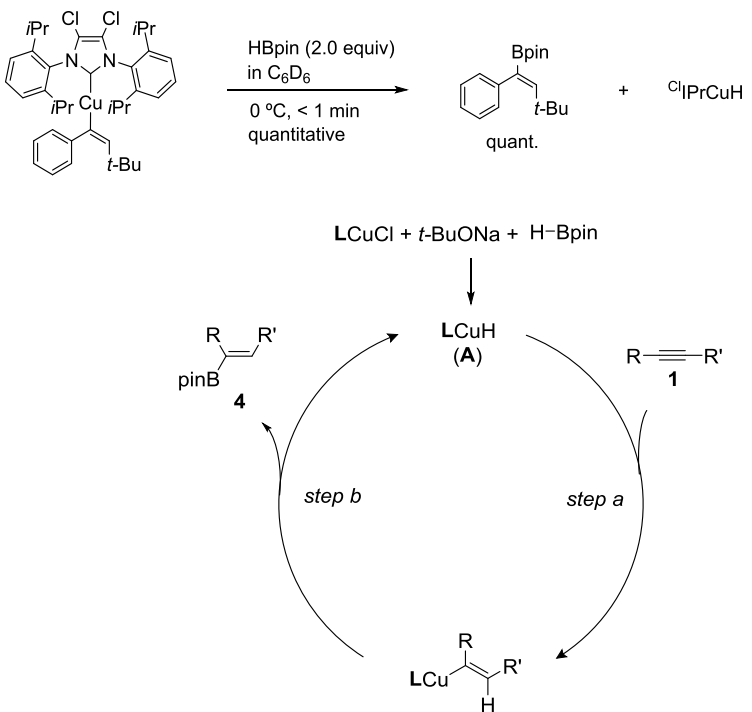

(B) 
Scheme 10 A possible catalytic cycle for the copper-catalyzed hydroborat ion of unsymmetrical internal alkynes with HBpin.

\section{Borylative transformation of alkynes catalyzed by a boryl copper species}

\subsection{Synthesis of boryl copper complexes}

Recent studies clearly show that a boryl copper species, generated by the transmetalation of bis(pinacolato)diboron (B2pin 2$)$ with an alkoxy or acetate copper species, is one of the most efficient borylation reagents. ${ }^{3,26}$ In 2005, Sadighi and co-workers reported that the reaction of $\operatorname{IPrCu}\left(\mathrm{O} t\right.$-Bu) with $\mathrm{B}_{2}$ pin 2 afforded a boryl copper complex, $\mathrm{IPrCu}$ (Bpin), and its structure was determined by the X-ray crystallographic analysis. ${ }^{27}$ We also determined the crystal structure of a borylcopper complex with ${ }^{\mathrm{Cl}} \mathrm{IPr}$ as the ligand (Scheme 11). ${ }^{28}$

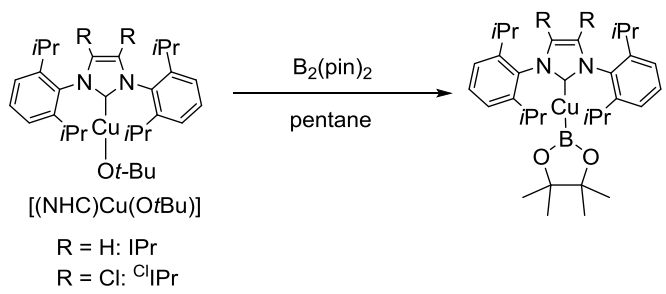

Scheme 11 Synthesis of boryl copper complexes.

\subsection{Copper-catalyzed hydroboration of terminal alkynes}

As mentioned in Section 2.4., the hydroboration with HBpin is a robust and practical synthetic method for the synthesis of organoboranes. ${ }^{20}$ In contrast, $B_{2}$ pin 2 may be a potentially effective borylation reagent. A pioneering work has been done by Miyaura and co-workers. ${ }^{26}$ They carried out the reaction of terminal alkynes with $\mathrm{B}_{2}$ pin 2 in the presence of a stoichiometric amount of $\mathrm{CuCl}$ and $\mathrm{AcOK}$ in $\mathrm{N}, \mathrm{N}$-dimethylformamide (DMF) (Scheme 12). Under the reaction conditions, a mixture of regioisomers of the hydroboration products was obtained. The additives such as $\mathrm{LiCl}$ or phosphines affected the yield and regioselectivity of the product.

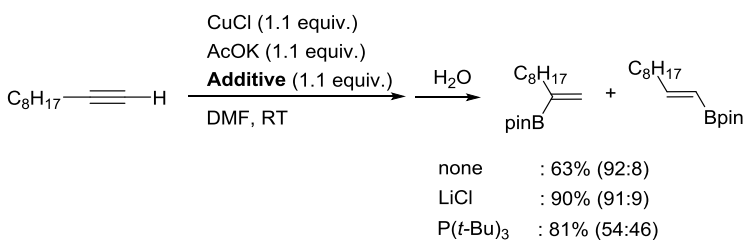

Scheme 12 Copper-mediated hydroboration of 1-decyne.

Hoveyda and co-workers reported the ligand-controlled regioselective borylation of terminal alkynes using a copper catalyst with different NHC ligands (Scheme 13 and 14). ${ }^{29}$ When the reaction of tert-butyl propargyl ether was carried out with an arylsubstituted NHC ligand (SIMes), $\alpha$-borylated product was obtained in $84 \%$ yield (Scheme 13). Propargyl amine derivatives also afforded the corresponding products in high yields. In the cases of arylacetylenes, $\alpha$-borylation reaction proceeded in the presence of the copper catalyst bearing SIPr as the ligand.

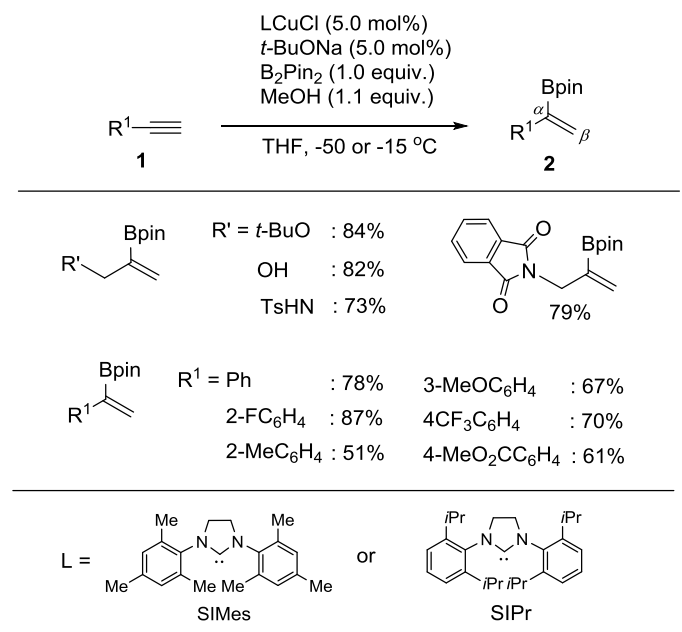

Scheme 13 Copper-catalyzed hydroboration of terminal alkynes, giving $\alpha$-borylated products.

Interestingly, the regioselectivity of borylation site was switched by using a NHC ligand bearing adamantyl groups (Scheme 14) ${ }^{29}$ The reaction of tert-butyl propargyl ether at $22{ }^{\circ} \mathrm{C}$ successfully afforded the $\beta$-borylated product in $80 \%$ yield. Strylene derivatibies were also converted to the corresponding $\beta$-products in good to high yields. Detailed mechanistic studies indicate that the selectivity arises from the structural and electronic properties of the NHC ligands and the alkyne substrates.

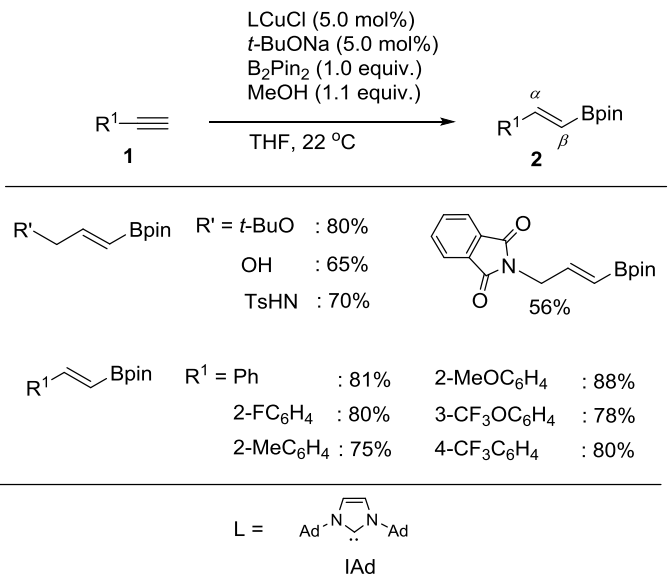

Scheme 14 Copper-catalyzed hydroboration of terminal alkynes, giving $\beta$-borylated products.

In addition, Hoveyda and co-workers also reported that vicinal diboronates were obtained by the reaction of terminal alkynes and $\mathrm{B}_{2}$ pin 2 in the presence of $\mathrm{CuCl}$ and a chiral NHC ligand (eq 4). ${ }^{30}$

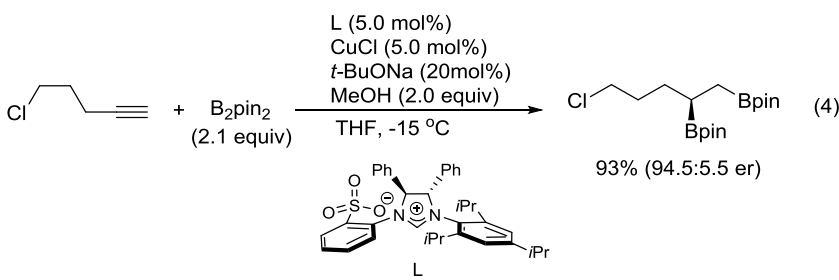




\subsection{Copper-catalyzed hydroboration of unsymmetrical internal alkynes}

Yun and co-workers achieved the first catalytic hydroboration of activated internal alkynes using a combination of $\mathrm{B}_{2}$ pin 2 and methanol $(\mathrm{MeOH})$ as the borylation reagent (Scheme 15a). ${ }^{31}$ The reaction of alkynoates with a catalytic amount of $\mathrm{CuCl} / t$ $\mathrm{BuONa} / \mathrm{Xan}$ in tetrahydrofuran (THF) at room temperature afforded the corresponding $\beta$-functional alkenylboronates in good to high yields and high regioselectivity. They also found that a copper catalyst with an imidazoline-2-thione (IMS) ligand catalyzed the hydroboration of aromatic internal alkynes (Scheme 15b). ${ }^{32}$ Although the reaction of 1-phenyl-1-propyne afforded the corresponding product in a high yield and with high regioselectivity, the reaction with 1-pheny-1-hexyne provided the product in a moderate yield and with moderate regioselectivity.

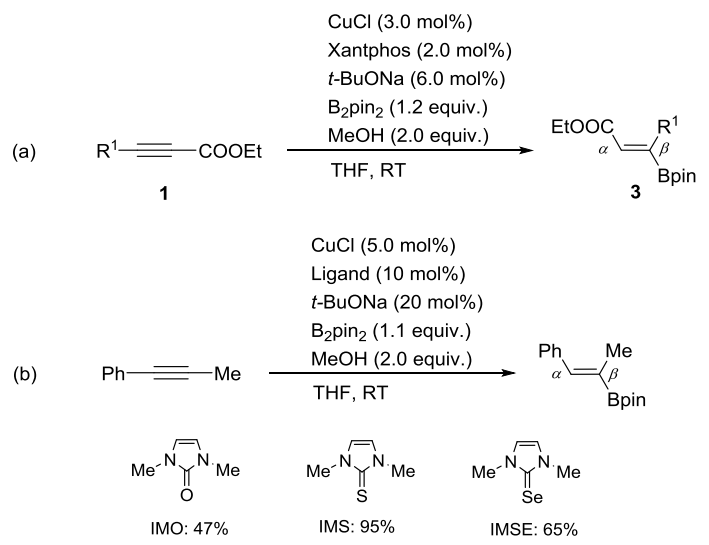

Scheme 15 Copper-catalyzed hydroboration of an alkynoate and 1-phenyl-1propyne employing $\mathrm{B}_{2}$ pin $_{2}$ and $\mathrm{MeOH}$.

In 2011, Yun and co-workers reported an improved catalytic system, $\mathrm{CuCl} / t-\mathrm{BuONa} / \mathrm{P}(p \text {-tol })_{3}$. (Scheme 16). ${ }^{33}$ Using this system, the reactions of internal alkynes afforded to the corresponding alkenyl boranes in good to high yields. In the case of unsymmetrical internal alkynes with phenyl and secondary alkyl groups, the corresponding products were obtained in high yields with moderate selectivity. $\mathrm{Ma}$ and co-workers also reported the hydroboration of unsymmetrical internal alkynes using $\mathrm{CuCl} / \mathrm{K}_{2} \mathrm{CO}_{3} / \mathrm{P}\left(p-\mathrm{MeOC}_{6} \mathrm{H}_{4}\right)_{3}$ catalyst system. ${ }^{34}$

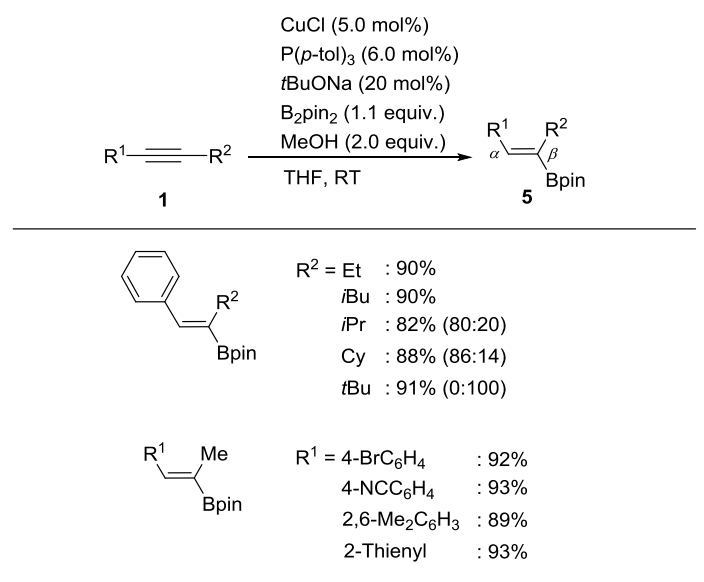

Scheme 16 Copper-catalyzed hydroboration of unsymmetrical internal alkynes employing $\mathrm{CuCl} / \mathrm{P}(o-\text { tol })_{3}$.

We developed the regioselective hydroboration of unsymmetrical internal alkynes using a copper catalyst with $\mathrm{CF}_{3} \mathrm{Ar}-\mathrm{Xan}$ as the ligand (Scheme 17). ${ }^{25}$ It is noteworthy that even when secondary alkyl moieties were attached to the acetylenic carbon, the regioselectivity of the $\beta$-products was high. The alkynes bearing conjugated ester and amide functionalities also afforded the respective $\beta$-products in high yields and with high regioselectivity.

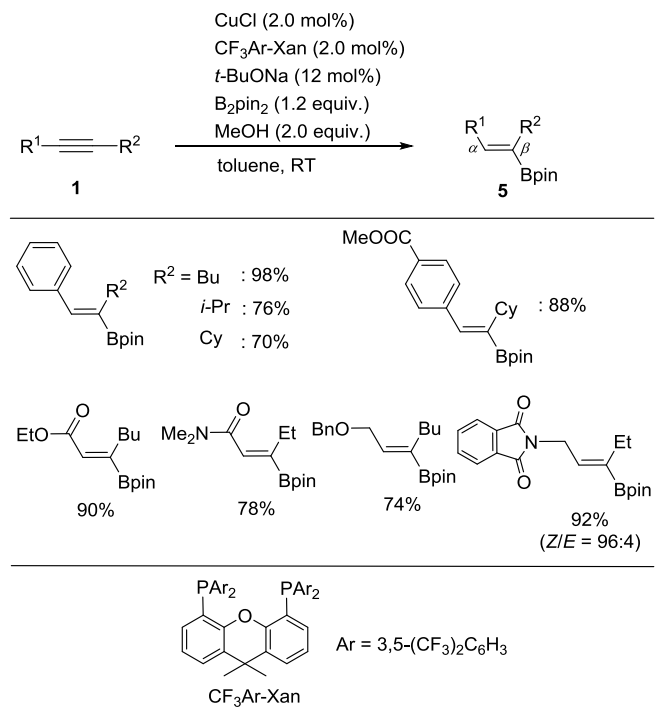

Scheme 17 Copper-catalyzed hydroboration of unsymmetrical internal alkynes employing $\mathrm{CuCl} / \mathrm{CF}_{3} \mathrm{Ar}-\mathrm{Xan}$.

Arrayás and Carretero also reported the regioselective borylation of propargyl-functionalized internal alkynes using a copper catalyst (Scheme 18). ${ }^{35}$ The reactions of propargylsubstituted 2-butynes were carried out using $\mathrm{CuCl} / \mathrm{PCy}_{3} / t$ $\mathrm{BuONa}$ in toluene at room temperature. The reaction of an alkyne bearing a thioether moiety afforded the corresponding product in $76 \%$ yield and with high regioselectivity. A sulfonylsubstituted alkyne was converted to the corresponding product in good yield. Interestingly, the reaction of 2-butynol successfully afforded the borylated allylic alcohol. The alkynes bearing a benzylether or silylether moiety provided the corresponding products in good yields and with high regioselectivity. In the case of homopropagylic ether as the functional group, a mixture of hydroborylated products was obtained.

For the hydroboration reactions using $\mathrm{B}_{2}$ pin, a boryl copper species ( $\mathrm{LCu}-\mathrm{B})$ may be generated as the catalytic species (Scheme 19). The addition of the LCu-B species to alkynes

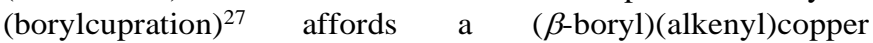
intermediate with high regioselectivity. Next, the protonation of the alkenylcopper species with $\mathrm{MeOH}$ provides a $\beta$-borylated product (5) efficiently. Finally, the reaction of the resulting $\mathrm{LCuOMe}$ with $\mathrm{B}_{2}$ pin 2 regenerates $\mathrm{LCu}-\mathrm{B}$, and the catalytic cycle is completed (step c). Through this mechanism, the regioselectivity can be successfully controlled in the borylcupration stage. 


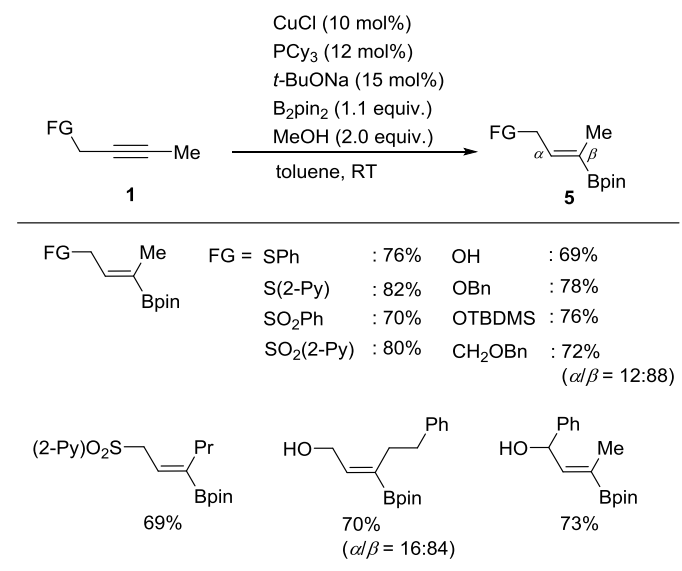

Scheme 18 Copper-catalyzed hydroboration of propagylic substituted alkynes.

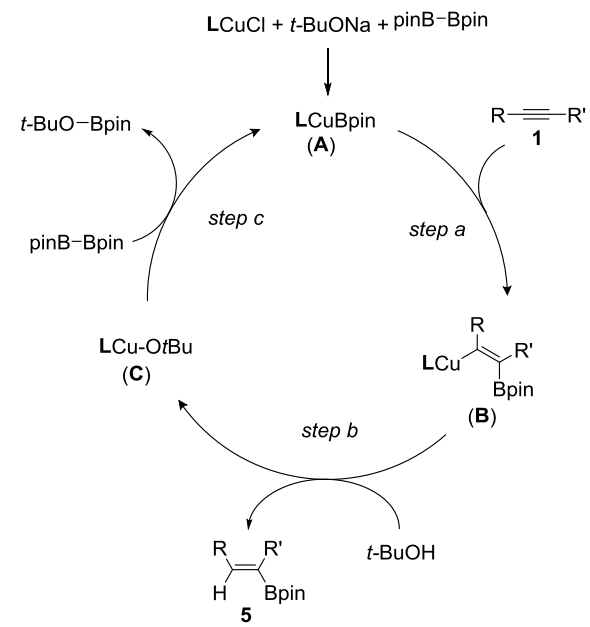

Scheme 19 A possible catalytic cycle for the copper-catalyzed hydroboration of alkynes with $\mathrm{B}_{2} \mathrm{pin}_{2} / \mathrm{ROH}$.

\subsection{Copper-catalyzed diboration of internal alkynes}

As mentioned above, the introduction of one boron moiety can be achieved by the hydroboration with $\mathrm{B}_{2} \mathrm{pin}_{2} / \mathrm{ROH}$. When two boron moieties are introduced onto an alkyne, the product may be a good intermediate for the synthesis of complex molecules. Yoshida and co-workers reported the copper-catalyzed diborylation of internal alkynes using $\mathbf{B}_{2}$ pin 2 and copper catalysts (Scheme 20). ${ }^{36}$ The reaction of 4-octyne with $\mathrm{B}_{2}$ pin 2 in the presence of a catalytic amount of $\mathrm{Cu}(\mathrm{OAc})_{2}$ and $\mathrm{PCy}_{3}$ in toluene at $80{ }^{\circ} \mathrm{C}$ afforded a cis-diborylated product (6) in $82 \%$ yield. The reaction of diphenylacetylene also gave the corresponding product in $78 \%$ yield. Other internal alkynes with various functionalities such as bromo and cyano groups were tolerated. Interestingly, the reaction of a propargyl ether with the $\mathrm{Cu}(\mathrm{OAc})_{2} / \mathrm{P}(t-\mathrm{Bu})_{3}$ catalyst system afforded a tetraborylated product in a good yield (eq. 5).

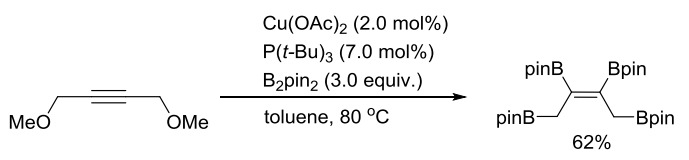

In addition, the catalyst system can be applied to the diborylation of arynes, to afford the 1,2-diborylbenzene derivatives in good to high yields.

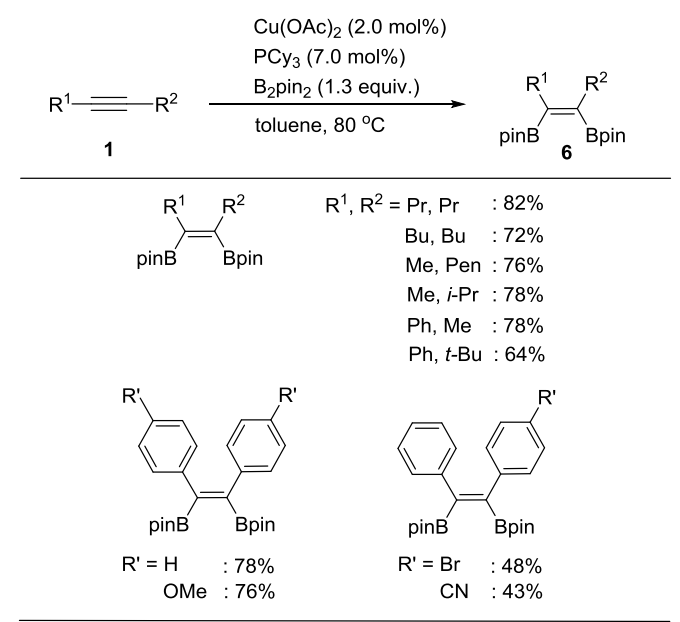

Scheme 20 Copper-catalyzed diborylation of alkynes.

Yoshida and co-workers also developed the stannylboration of internal alkynes using $\mathrm{B}_{2}$ pin2 as the borylation reagent and alkoxystannanes $\left(\mathrm{Bu}_{3} \mathrm{SnOR}, \mathrm{R}=\mathrm{Me}\right.$ or $\left.t-\mathrm{Bu}\right)$ as the stannylation reagent. ${ }^{37}$

\subsection{Copper-catalyzed carboboration of alkynes}

The introduction of a boron moiety into an alkyne along with the simultaneous carbon-carbon bond formation is named as the carboboration reaction. The pioneering work has been reported by Suginome and co-workers using palladium or nickel catalysts via the direct activation of a boron-carbon bond. ${ }^{38}$ In contrast, Tortosa $^{39}$ and Yoshida ${ }^{40}$ independently reported the coppercatalyzed carboboration of alkynes using $\mathrm{B}_{2}$ pin 2 and carbon electrophiles such as alkyl halides (Scheme 21 and 22).

Tortosa and co-workers found that the reaction of phenylacetylene, $\mathrm{B}_{2}$ pin2, and $\mathrm{MeI}$ in the presence of $t$-BuONa and a copper catalyst with Xantphos as the ligand afforded the methylborated product (7) in $74 \%$ yield and with high regioselectivity (Scheme 21). ${ }^{39}$ The catalyst system was effective for diverse terminal alkynes with various functional groups such as ester and bromo moieties. The reaction of diphenylacetylene was converted to the corresponding product in a moderate yield. The reaction of 1-phenyl-1-propyne with benzyl bromide as the electrophile afforded a mixture of regioisomers in $55 \%$ total yield and with a moderate regioselectivity.

Yoshida and co-workers reported that a mixture of $\mathrm{Cu}(\mathrm{OAc})_{2} / \mathrm{PCy}_{3}$ catalyzed the reaction of diphenylacetylene, $\mathrm{B}_{2}$ pin 2 , and benzyl chloride in the presence of $t$-BuOK in DMF at $50{ }^{\circ} \mathrm{C}$, to afford the desired carboborated product in $67 \%$ yield (Scheme 22). ${ }^{40}$ The reaction of diverse internal alkynes gave the corresponding products in good yields. The reaction of 1-phenyl1 -propyne afforded the $\beta$-borylated product regioselectively in $54 \%$ yield. They successfully established the carboboration of alkenes using SIMesCuCl as the catalyst (eq. 6).

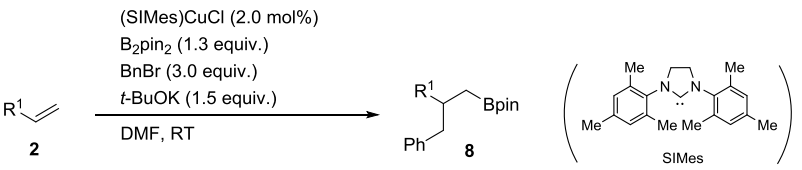




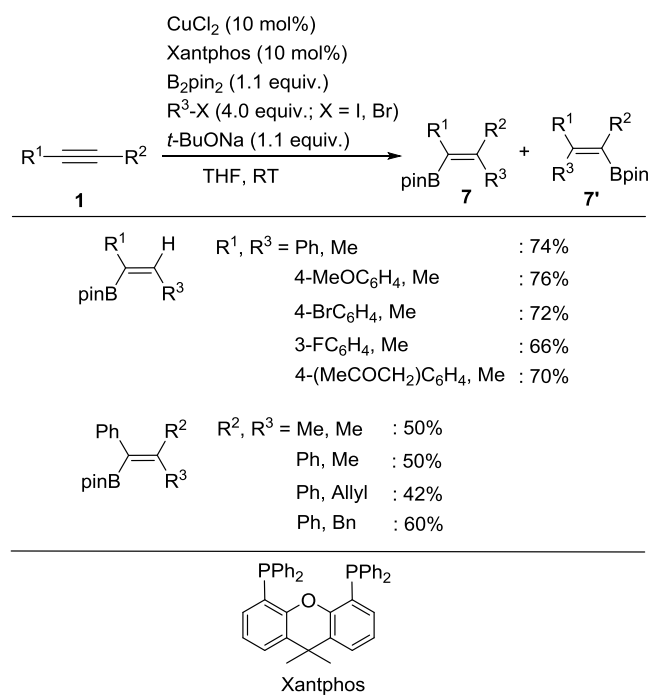

Scheme 21 Copper-catalyzed carboboration of alkynes employing $\mathrm{CuCl} / \mathrm{Xantphos}$.

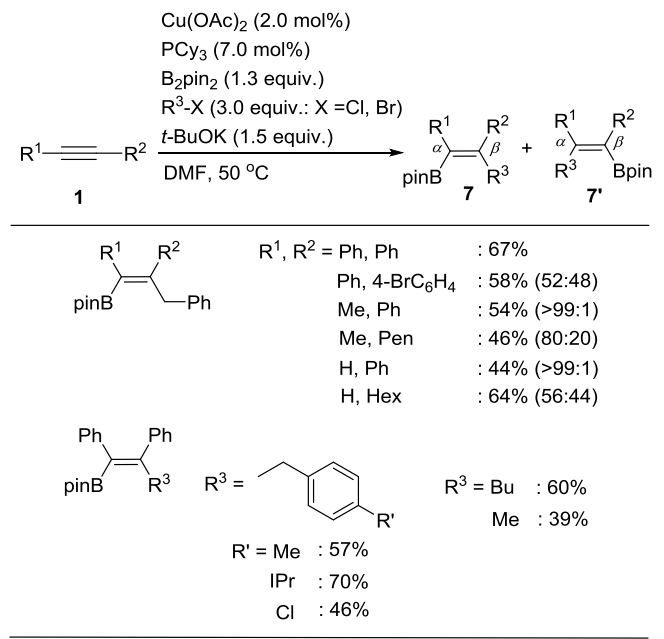

Scheme 22 Copper-catalyzed carboboration of alkynes employing $\mathrm{Cu}(\mathrm{OAc})_{2} / \mathrm{PCy}_{3}$.

Scheme 23 shows a plausible mechanism. The reaction of $\mathrm{LCu}(\mathrm{O} t$ - $\mathrm{Bu})$ with $\mathrm{B}_{2}$ pin2 affords a boryl copper intermediate (A). The syn addition of $\mathbf{A}$ to alkynes (borylcupration) affords a ( $\beta$ boryl)(alkenyl)copper intermediate (B). The nucleophilic addition of the alkenylcopper species to a carbon electrophile gives the desired carboborated product (7) and a copper halide. Finally, the reaction of the copper halide $(\mathbf{C})$ and $t$-BuOM $(\mathrm{M}=$ $\mathrm{Na}$ or $\mathrm{K}$ ) affords $\mathrm{LCu}(\mathrm{O} t-\mathrm{Bu})$ and the catalytic cycle closes. Yoshida proposed the reaction to proceed via an intermediate $\mathbf{E}$, which was formed by the reaction of $\mathbf{B}$ with alkoxide in situ. ${ }^{40}$

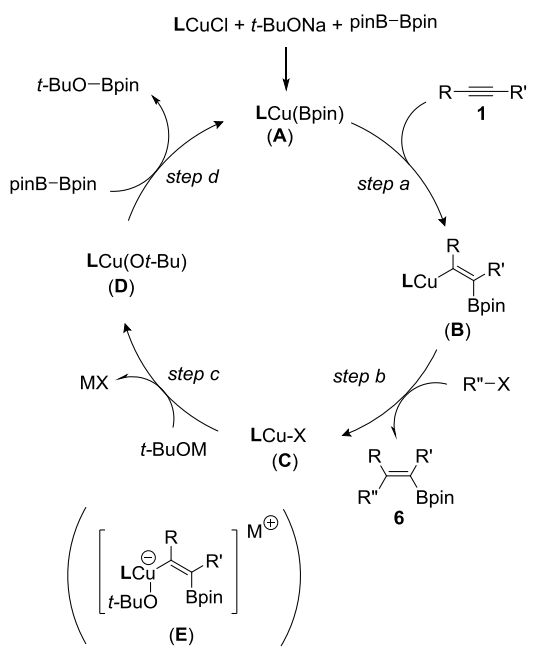

Scheme 23 A possible catalytic cycle for the copper-catalyzed carboboration of alkynes with $\mathrm{B}_{2}$ pin 2 and carbon electrophiles.

\subsection{Copper-catalyzed boracarboxylation of alkynes}

The fixation of $\mathrm{CO}_{2}$ along with the simultaneous introduction of a boron moiety is interesting because of the $\mathrm{CO}_{2}$ fixation and the synthesis of multi-functional conjugated carboxylic acids. Hou and co-workers reported the first catalytic boracarboxylation of alkyne using $\mathrm{CO}_{2}$ and $\mathrm{B}_{2}$ pin 2 in the presence of a stoichiometric amount of $t$-BuOLi and a copper catalyst (Scheme 24). ${ }^{41}$ The reaction of diphenylacetylene in $\mathrm{THF}$ at $80{ }^{\circ} \mathrm{C}$ afforded the boracarboxylated product in $81 \%$ yield. Diverse aromatic internal alkynes with different functional groups such as ester and chloro moieties gave the corresponding products in good to high yields.

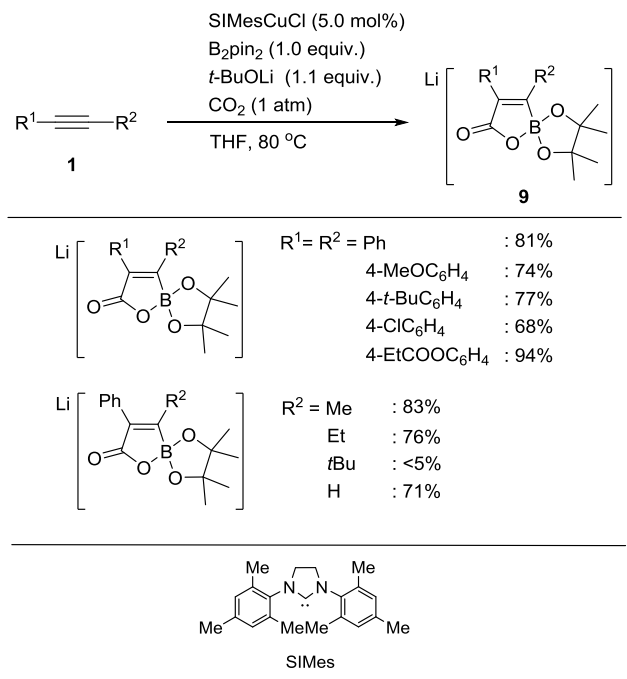

Scheme 24 Copper-catalyzed boracarboxylation of alkynes employing $\mathrm{CO}_{2}$ and $\mathrm{B}_{2}$ pin2.

Notably, the structures of all intermediates synthesized by the stoichiometric reactions were determined by X-ray crystallographic analysis (Scheme 25). A possible catalytic cycle is described as follows: First, the reaction of $\operatorname{IPrCu}(\mathrm{O} t-\mathrm{Bu})$ with $B_{2}$ pin 2 affords a boryl copper complex, $\operatorname{IPrCu}(\mathrm{Bpin})(\mathbf{A})$. The reaction of $\mathbf{A}$ with diphenylacetylene gives a $(\beta-$ 
boryl)(alkenyl)copper complex (B). The reaction of $\mathbf{B}$ with $\mathrm{CO}_{2}$ in THF affords a copper complex $\mathbf{C}$. The transmetalation between $\mathbf{C}$ and $t$-BuOLi regenerates $\operatorname{IPrCu}(\mathrm{O} t$ - $\mathrm{Bu})$.

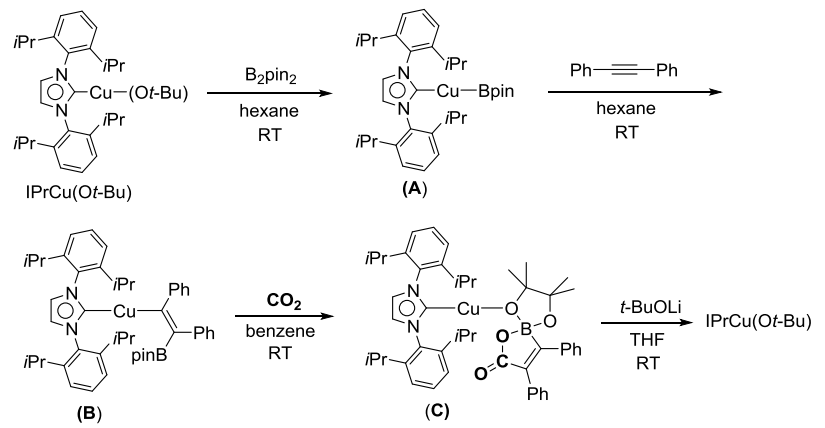

Scheme 25 Stoichiometric reactions for the copper-catalyzed boracarboxylation of alkynes employing $\mathrm{CO}_{2}$ and $\mathrm{B}_{2}$ pin 2 .

Regarding the heterocarboxylation, we have developed the copper-catalyzed silacarboxylation of alkynes with $\mathrm{CO}_{2}$ and silylborane, as the silylation reagent, in the presence of a catalytic amount of $\left[\mathrm{CuCl}\left(\mathrm{PCy}_{3}\right)\right]_{2} /\left(\mathrm{NaO} t\right.$-Bu) (eq. 7). ${ }^{42}$

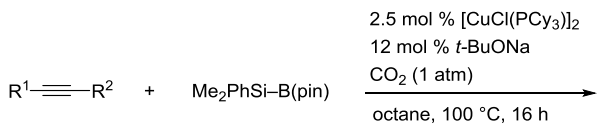

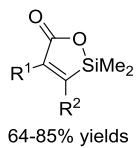

$64-85 \%$ yields

\section{Conclusions}

The transformation of alkynes using a copper hydride $(\mathrm{Cu}-\mathrm{H})$ or boryl copper $(\mathrm{Cu}-\mathrm{B})$ species as the catalytically active species is one of the most efficient methods to afford multi-substituted alkenes. The transformation proceeds via the regioselective addition of the $\mathrm{Cu}-\mathrm{H}$ or $\mathrm{Cu}-\mathrm{B}$ species to an alkyne, to afford the corresponding alkenylcopper intermediate. The reactions of the alkenylcopper with various electrophiles such as alcohol, carbon dioxide $\left(\mathrm{CO}_{2}\right)$, or alkyl halide afforded the corresponding multisubstituted alkenes that are potentially good intermediate in organic synthesis. The semihydrogenation, hydrocarboxylation, and hydroboration of alkynes have been developed using $\mathrm{Cu}-\mathrm{H}$ as the active species. The hydroboration, diboration, carboboration and boracarboxylation of alkynes involve the $\mathrm{Cu}$ B species.

Regarding the reductive transformations such as semihydrogenation of hydrocarboxylation, the use of hydrogen gas $\left(\mathrm{H}_{2}\right)$ should be one of the most important tasks. In this case, activation of $\mathrm{H}_{2}$ by a copper catalyst must be a key step. The selective introduction of boron moiety is very important reaction for further organic synthesis. Copper complexes realized the regio- and setereoselective introduction of boron moiety to unsymmetrical internal alkynes. The results would be applicable to other various carbon-carbon multiple bonds. Hopefully, the methodology will contribute to efficient syntheses of many valuable molecules with shorter steps.

\section{Notes and references}

1 The Chemistry of Organocopper Compounds, Z. Rappoport and I. Marek eds., WILEY, West Sussex, 2009.

2 (a) S. Díez-González and S. P. Nolan, Acc. Chem. Res., 2008, 41, 349-358, (b) C. Deutsch, N. Krause and B. H. Lipshutz, Chem. Rev., 2008, 108, 2916-2927. (c) S. Rendler and M. Oestreich, Angew. Chem. Int. Ed., 2007, 46, 498-504. (d) B. H. Lipshutz, Synlett, 2009, 509-524.

3 J. Yun, Asian J. Org. Chem., 2013, 2, 1016-1025.

4 S. A. Bezman, M. R. Churchill, J. A. Osborn and J. Wormald, J. Am. Chem. Soc., 1971, 93, 2063-2065.

5 W. S. Mahoney, D. M. Brestensky and J. M. Stryker, J. Am. Chem. Soc., 1988, 110, 291-293.

6 D. M. Brestensky, D. E. Huseland, C. McGettigan and J. M. Stryker, Tetrahedron Lett., 1988, 29, 3749-3752.

7 (a) W. A. Herrmann, Angew. Chem. Int. Ed., 2002, 41, 1290-1309; (b) V. César, S. Bellemin-Laponnaz and L. H. Gade, Chem. Soc. Rev., 2004, 33, 619-636; (c) D. Bourissou, O. Guerret, F. P. Gabbaï and G. Bertrand, Chem. Rev., 2000, 100, 39-92, and references cited therein.

8 N. P. Mankad, D. S. Laitar and J. P. Sadighi, Organometallics, 2004, 23, 3369-3371.

9 S. D.-González, H. Kaur, F. K. Zinn, E. D. Stevens and S. P. Nolan, J. Org. Chem., 2005, 70, 4784-4796.

10 T. Fujihara, K. Semba, J. Terao and Y. Tsuji, Angew. Chem. Int. Ed., 2010, 49, 1472-1476.

11 (a) H. Lindlar, Helv. Chim. Acta, 1952, 35, 446-450.(d) H. Lindlar and R. Dubuis, Org. Synth., 1966, 46, 89-91.

12 (a) J. Li and R. Hua, Chem. Eur. J., 2011, 17, 8462-8465. (b) C. Belger, N. M. Neisius and B. Plietker, Chem. Eur. J., 2010, 16, 12214-12220. (c) Y. Shvo, I. Goldverg, D. Czerkie, D. Reshef and Z. Stein, Organometallics, 1997, 16, 133-138. (d) H. S. L. Pierre, J. Arnold and F. D. Toste, Angew. Chem. Int. Ed., 2011, 50, 3900-3903. (e) T. L. Gianetti, N. C. Tomson, J. Arnold and R. G. Bergman, J. Am. Chem. Soc., 2011, 133, 14904-14907.

13 (a) R. Shen, T. Chen, Y. Zhao, R. Qiu, Y. Zhou, S. Yin, W. Wang, M. Goto and L.-B. Han, J. Am. Chem. Soc., 2011, 133, 17037-17044. (b) P. Hauwert, R. Boerleider, S. Warsink, J. J. Weigand and C. J. Elsevier, J. Am. Chem. Soc., 2010, 132, 16900-16910. (c) J. Li, R. Hua and T. Liu, J. Org. Chem., 2010, 75, 2966-2970. (d) P. Hauwert, G. Maestri, J. W. Sprengers, M. Catellani and C. J. Elsevier, Angew. Chem. Int. Ed., 2008, 47, 3223-3226.

14 J. F. Daeuble, C. McGettigan, and J. M. Stryker, Tetrahedron Lett., 1990, 31, 2397-2400.

15 K. Semba, T. Fujihara, T. Xu, J. Terao and Y. Tsuji, Adv. Synth. Catal., 2012, 354, 1542-1550.

16 A. M. Whittaker and G. Lalic, Org. Lett., 2013, 15, 1112-1115.

17 (a) Y. Tsuji and T. Fujihara, Chem. Commun., 2012, 48, 9956-9964. (b) L. Zhang and Z. Hou, Chem. Sci., 2013, 4, 3395-3403. (c) K. Huang, C.-L. Sun and Z.-J. Shi, Chem. Soc. Rev., 2011, 40, 24352452. (d) M. Cokoja, C. Bruckmeier, B. Rieger, W. A. Herrmann and F. E. Kühn, Angew. Chem. Int. Ed., 2011, 50, 8510-8537. (e) S. N. Riduan and Y. Zang, Dalton Trans., 2010, 39, 3347-3357.

18 (a) J. Takaya and N. Iwasawa, J. Am. Chem. Soc., 2008, 130, 1525415255. (b) C. M. Williams, J. B. Johnson and T. Rovis, J. Am. Chem. Soc., 2008, 130, 14936-14937. (c) Y. Zhang and S. N. Riduan, Angew. Chem. Int. Ed., 2011, 50, 6210-6212. 
19 (a) T. Fujihara, T. Xu, K. Semba, J. Terao and Y. Tsuji, Angew. Chem. Int. Ed., 2011, 50, 523-527. (b) S. Li, W. Yuan and S. Ma, Angew. Chem. Int. Ed., 2011, 50, 2578-2582.

20 (a) H. C. Brown, Pure Appl. Chem., 1976, 47, 49-60. (b) I. Beletskaya and A. Pelter, Tetrahedron, 1997, 53, 4957-5026. (c) A.M. Carroll, T. P. O'Sullivan and P. J. Guiry, Adv. Synth. Catal. , 2005, 347, 609-631.

21 (a) N. Miyaura and A. Suzuki, Chem. Rev., 1995, 95, 2457-2483. (b) In Metal-Catalyzed Cross-Coupling Reaction (Eds.: A. de Meijere, and F. Diederich), Wiley-VCH: Weinheim, 2004; Vol. 1, pp 41-123. (a) A. Pelter, B. Singaram and H. Brown, Tetrahedron Lett., 1983, 24, 1433-1436. (b) C. E. Tucker, J. Davidson and P. Knochel, J. Org. Chem., 1992, 57, 3482-3485. (c) S. Pereira and M. Srebnik, Organometallics, 1995, 14, 3127-3128. (d) T. Ohmura, Y. Yamamoto and N. Miyaura, J. Am. Chem. Soc., 2000, 122, 49904991. (e) Y. D. Wang, G. Kimball, A. S. Prashad and Y. Wang, Tetrahedron Lett., 2005, 46, 8777-8780. (f) H. Jang, A. R. Zhugralin, Y. Lee and A. H. Hoveyda, J. Am. Chem. Soc., 2011, 133, 7859-7871.

23 (a) H. C. Brown and S. K. Gupta, J. Am. Chem. Soc., 1972, 94, 43704371. (b) X. He and J. F. Hartwig, J. Am. Chem. Soc., 1996, 118, 1696-1702. (c) T. Konno, J. Chae, T. Tanaka, T. Ishihara and H. Yamanaka, Chem. Commun., 2004, 690-691.

24 B. H. Lipshutz, Ž. V. Bošković and D. H. Aue, Angew. Chem. Int. Ed., 2008, 47, 10183-10186.

25 K. Semba, T. Fujihara, J. Terao and Y. Tsuji, Chem. Eur. J., 2012, 18, 4179-4184.

26 (a) K. Takahashi, T. Ishiyama and N. Miyaura, Chem. Lett. 2000, 982-983. (b) K. Takahashi, T. Ishiyama and N. Miyaura, J. Organomet. Chem., 2001, 625, 47-53. (c) H. Ito, H. Yamanaka, J. Tateiwa and A. Hosomi, Tetrahedron Lett. 2000, 41, 6821-6825.

27 D. S. Laitar, P. Müller and J. P. Sadighi, J. Am. Chem. Soc., 2005, 127, 17196-17197.
28 K. Semba, M. Shinomiya, T. Fujihara, J. Terao and Y. Tsuji, Chem. Eur. J., 2013, 19, 7125-7132.

29 H. Jang, A. R. Zhugralin, Y. Lee, and A. H. Hoveyda, J. Am. Chem. Soc., 2011, 133, 7859-7871.

30 Y. Lee, H. Jang, and A. H. Hoveyda, J. Am. Chem. Soc., 2009, 131, 18234-18235.

31 J.-E. Lee, J. Kwon and J. Yun, Chem. Commun., 2008, 733-734.

32 H. R. Kim, I. G. Jung, K. Yoo, K. Jang, E. S. Lee, J. Yun and S. U. Son, Chem. Commun., 2010, 46, 758-760.

33 H. R. Kim and J. Yun, Chem. Commun., 2011, 47, 2943-2945.

34 W. Yuana and S. Ma, Org. Biomol. Chem., 2012, 10, 7266-7268.

35 A. L. Moure, R. G. Arrayas, D. J. Cardenas, I. Alonso and J. C. Carretero, J. Am. Chem. Soc., 2012, 134, 7219-7222.

36 H. Yoshida, S. Kawashima, Y. Takemoto, K. Okada, J. Ohshita and K. Takaki, Angew. Chem. Int. Ed., 2012, 51, 235-238.

37 Y. Takemoto, H. Yoshida and K. Takaki, Chem. Eur. J., 2012, 18, 14841-14844.

38 (a) M. Suginome, A. Yamamoto and M. Murakami, J. Am. Chem. Soc., 2003, 125, 6358-6359. (b) M. Suginome, A. Yamamoto and M. Murakami, Angew. Chem. Int. Ed., 2005, 44, 2380-2382. (c) M. Suginome, M. Shirakura and A. Yamamoto, J. Am. Chem. Soc., 2006, 128, 14438-14439.

39 R. Alfaro, A. Parra, J. Alemán, J. L. G. Ruano and M. Tortosa, J. Am. Chem. Soc., 2012, 134, 15165-15168.

40 H. Yoshida, I. Kageyuki and K. Takaki, Org. Lett., 2013, 15, 952-955.

41 L. Zhang, J. Cheng, B. Carry and Z. Hou, J. Am. Chem. Soc., 2012, 134, 14314-14317.

42 T. Fujihara, Y. Tani, K. Semba, J. Terao and Y. Tsuji, Angew. Chem. Int. Ed., 2012, 51, 11487-11490. 